УДК 699.85:621.039.743

\title{
СОЗДАНИЕ ПОДЗЕМНЫХ ПРОТИВОФИЛЬТРАЦИОННЫХ ЭКРАНОВ С ПОМОЩЬЮ НАПРАВЛЯЮЩИХ СКВАЖИН И ШНЕКОВОГО УСТРОЙСТВА
}

\author{
Менейлюк Александр Иванович'1, \\ meneilyk@gmail.com
}

\section{Никифоров Алексей Леонидович1,} nikiforov.aleksey@yahoo.com

\author{
Менейлюк Иван Александрович², \\ ivmen11112019@gmail.com
}

\author{
Руссый Виктор Викторович1, \\ viruswot@gmail.com \\ 1 Одесская государственная академия строительства и архитектуры, \\ Украина, 65029, г. Одесса, ул. Дидрихсона, 4. \\ 2 Харьковский национальный университет строительства и архитектуры, \\ Украина, 61000, г. Харьков, ул. Сумская, 40.
}

\begin{abstract}
Актуальность. Одним из путей обеспечения экологической безопасности является локализация действующих и потенциальных источников загрязнения путем устройства защитного экрана. Для этого рациональным представляется устройство подземных противофильтрационных экранов под источником загрязнения, препятствующих эмиссии радиоактивных частии в окружающую среду, в частности, загрязнению подземных вод. Данное исследование посвящено разработке шнековой технологии устройства противофильтрационного экрана, которая заключается в устройстве направляющих скважин методом горизонтально направленного бурения с последующим устройством водонепроницаемого слоя с помощью замены грунта шнеком на специальный бетонный раствор.

Цель: экспериментальное обоснование эфффективности шнековой технологии устройства подземных противофильтрационных экранов для обеспечения радиационной безопасности объектов.

Объект: устройство подземных противофильтрационных экранов с помощью шнековой технологии.

Методы: экспериментально-статистическое моделирование, лабораторный эксперимент, корреляционно-регрессионный анализ.

Результаты. Для сооружений небольшой ширины (10-20 м) допускается медленное бетонирование со скоростью 5-6 м/4 (угловая скорость 1,5 c-1 и производительность подачи состава 50 м/ч). Для сооружений большой ширины (40-60 м) подходят составы с большим временем набора пластической прочности при концентрации фрибры (9 \%), бентонита (5\%) и жидкого стекла (6 \%). При этом скорость бетонирования должна быть максимальной (10-11 м/4 при угловой скорости 0,5 $\mathrm{c}^{-1}$ и производительности подачи состава $\left.30 \mathrm{~m}^{3} / 4\right)$. Предельно большая скорость бетонирования достигается при угловой скорости $1,5 \mathrm{c}^{-1}$ и тяговом усилии 50,96 Н. Дальнейшее увеличение угловой скорости является нецелесообразньм, так как при большей скорости вращения (более $1,5 \mathrm{c}^{-1}$ ) наблюдались сильные вибрации и обвалы грунта. Эти экспериментальные результаты позволили разработать технологические рекомендации по устройству противофильтрационных экранов шнековой технологией. А именно, разработать концепцию и порядок производства работ, рассчитать затраты труда и машинного времени.
\end{abstract}

\section{Ключевые слова:}

Экологическая безопасность, шнековая технология, горизонтально направленное бурение, противофильтрационный экран, экспериментально-статистическое моделирование.

\section{Введение}

Анализ проблем, возникающих при захоронении последствий аварии на Чернобыльской АЭС, показал, что по масштабам воздействия и необходимым финансовым и техническим ресурсам ведущее место занимает локализация загрязнений и снижение эмиссии радиоактивных веществ в подземные воды. Устройство противофильтрационных экранов способом горизонтально направленного бурения может быть использовано для защиты подземных вод от миграции загрязняющих веществ. Были предложены многочисленные способы устройства защитных экранов, однако их анализ показал низкую экономическую и экологическую эффективность. По этим критериям использование горизонтально направленного бурения более предпочтительно. В последние годы был разработан ряд технологий (инъекционная технология А.Ф. Петровского, ножевая технология А.М. Галинского), использующих горизонтально направленное бурение для устройства противофильтрационных экранов. Поисковые исследования показали, что применение шнековой технологии может дать более надёжный экран при меньших затратах на его изготовление.

\section{Анализ литературных данных}

Большое количество исследований показывает, что земля и подземные воды в зоне 30 км вокруг места Чернобыльской аварии заражены большим количеством радионуклидов. Почти все радиоактивные элементы сосредоточены в заглубленном слое земли $[1,2]$. Исследования [3] показывают, что наиболее 
опасным путём распространения радионуклидов являются подземные воды. Также установлено [4], что радиоактивные подземные воды способны загрязнять окружающую среду в течение долгого времени.

Устройство подземных противофильтрационных экранов под источниками загрязнения способно обеспечить экологическую безопасность. Среди технологий, которые могут обеспечить противофильтрационную защиту подземного пространства, следует отметить инъекцию грунта $[5,6]$, устройство фибробетонных защитных конструкций [7] и другие. Также существуют комбинации данных технологий, в частности, для решения проблемы локализации загрязненных почв [8]. Наиболее актуальными для устройства подземных противофильтрационных экранов являются технологии с применением горизонтально направленного бурения. Инъекционная технология А.Ф. Петровского $[9,10]$ предполагает устройство серии направляющих скважин, с помощью которых подаётся инъекционный раствор, превращающий слой грунта в водонепроницаемый экран. Однако из-за отсутствия рабочего органа невозможно достоверно утверждать, что после применения данной технологии обеспечена сплошность экрана, что приводит к необходимости избыточного расхода инъекционного состава. Ножевая технология А.М. Галинского [11] основана на устройстве направляющих скважин с последующим протягиванием по ним ножа, «разрезающего» толщу грунта. В образовавшуюся полость подаётся раствор, образующий противофильтрационный экран. Однако для движения рабочего органа в толще грунта требуются значительные усилия, которые могут разорвать уже устроенные участки экрана. Возможной альтернативой данным технологиям может стать способ, предполагающий устройство направляющих скважин и рабочего органа, испытывающего меньшее сопротивление в грунте, например, шнек. Кроме того, в последнее время появились технологии горизонтально-направленного бурения, позволяющие повышать усилия в направляющих скважинах $[12,13]$ и делать их криволинейными.

Определение оптимальных технологических режимов при строительстве или реконструкции инженерных сооружений возможно с применением экспериментально-статистического моделирования $[14,15]$ Особенностям и методике этого способа исследования посвящены ряд классических работ, среди которых $[16,17]$.

Проведенные исследования по подбору водонепроницаемых растворов показывают, что для использования в подземных сооружениях часто применяется бентонит, жидкое стекло, инъекционные смолы [18, 19]. В рамках предлагаемой шнековой технологии растворы применяются для создания грунтобетонного экрана путем смешивания с существующим грунтом под сооружением. Применение существующих технологий уплотнения бетонной смеси не представляется возможным, поэтому используемые растворы имеют высокое водоцементное отношение. Полученные результаты показывают, что применение добавки бентонита и жидкого стекла эффективно в бетонах с высоким водоцементным отношением. С учетом загущающего эффекта бентонит может быть использован для снижения водоотделения и расслоения высокопластичных и литых бетонных смесей [20].

Таким образом, можно заключить, что актуальной является проблема обеспечения радиационной безопасности подземного пространства в местах распространения радиоактивных элементов, например, могильников остатков Чернобыльской аварии. Эта проблема может быть решена путём устройства противофильтрационных экранов с применением технологий горизонтально направленного бурения. Подобные технологии показали низкую эффективность, поэтому требуется разработка и экспериментальное обоснование новой эффективной технологии, устраняющей прежние недостатки.

\section{Цель и задачи исследования}

Целью исследования является экспериментальное обоснование эффективности шнековой технологии устройства подземных противофильтрационных экранов для обеспечения радиационной безопасности объектов. Эта новая технология позволит экономичным индустриальным способом защитить подземное пространство от радиационного загрязнения. Задачи исследования:

- обосновать актуальность и способы разработки технологии устройства подземных противофильтрационных экранов для обеспечения радиационной безопасности объектов;

- оптимизировать скорость разработки грунта при изменении угловой скорости вращения шнека и тягового усилия;

- найти рациональную скорость бетонирования при изменении производительности подачи состава в полость экрана и угловой скорости вращения шнека;

- выполнить внедрение результатов исследования путём разработки технологических рекомендаций по новой технологии.

\section{Материалы, оборудование и методика экспериментальных исследований шнековой технологии устройства противофильтрационного экрана}

В работе предложена методика для определения фильтрационных характеристик в лабораторном стенде, а также проведён анализ результатов исследований процесса создания противофильтрационных экранов. Определены аналитические и графические зависимости показателя от технологических режимов. В исследовании определен оптимальный режим бурения и бетонирования по критерию стоимости путем выполнения анализа аналитических и графических зависимостей фильтрационных характеристик от исследуемых технологических факторов. Для реализации описанных задач разработана общая методика исследования (рис. 1).

Под противофильтрационным экраном подразумевается подземное сооружение, имеющее целью препятствовать подтоплению сооружений загрязненными водами либо сбросу загрязненных стоков из объ- 
екта локализации радиационных отходов. Это сооружение состоит из грунта основания, приобретающего противофильтрационные свойства вследствие перемешивания грунта с раствором.

Обоснование направления работы и определение актуальности темы Justification of the research topic relevance

\begin{tabular}{|c|}
\hline $\begin{array}{c}\text { Анализ известных источников по теме исследования } \\
\text { Analysis of well-known sources on the research topic }\end{array}$ \\
\hline $\begin{array}{c}\text { Постановка цели и задач исследования } \\
\text { Statement of the purpose and objectives of the study }\end{array}$ \\
\hline $\begin{array}{c}\text { Создание лабораторного стенда для проведения экспериментальных исследований } \\
\text { Development of a laboratory stand for experimental research }\end{array}$ \\
\hline
\end{tabular}

Выполнение экспериментов по определению пластической прочности, скорости бетонирования Performing experiments to determine plastic strength setting, speed of concreting

Получение экспериментальных данных по технологическим режимам устройства экрана Obtaining experimental data on selection of the composition of the injected solution and the technological modes of the shield arrangement

\section{(n) \\ Обработка и анализ результатов исследования \\ Processing and analysis of research results \\ Разработка технологической карты по устройству защитного экрана с использованием шнековой технологии \\ Development of the technological map for construction of a protective shield using auger technology}

Рис. 1. Общая методика исследования

Fig. 1. General methodology of the research

В экспериментальных исследованиях был использован лабораторный стенд, моделирующий распространение раствора в рассматриваемой толще грунта. Под влиянием переменных комбинаций технологических режимов инъецируемый раствор образует модель защитного экрана с различной противофильтрационной способностью. Ящик для грунта имеет размеры $60 \times 60 \times 60$ см исходя из длины шнека (50 см) плюс диаметр направляющей скважины - 10 см. Материал для изготовления ящика - лист OSB. Для передачи вращения шнека и направления разработки скважины в ящике выпилены продольные отверстия. Для устройства наклонных прямоугольных скважин противофильтрационного экрана отверстия для шнека расположены под углом $30^{\circ}$. Направляющая скважина в экспериментальном исследовании образуется при помощи установки поливинилхлоридной трубы диаметром 10 см, которая используется как форма и после уплотнения грунта удаляется. Ме- тодика создания экспериментальных образцов в лабораторном стенде показана на рис. 2.

Для определения характеристик грунта были использованы следующие приборы и оборудование:

- весы лабораторные по ГОСТ 24104-88;

- весы для гидростатического взвешивания по ГОСТ 29329;

- шкаф сушильный, обеспечивающий сушку при температуре $(105 \pm 10){ }^{\circ} \mathrm{C}$;

- противень;

- сосуд для насыщения образцов водой;

- проволочная щетка.

Влажность определялась путем сравнения массы песка в состоянии естественной влажности и после высушивания. Навеска массой 1000 г песка насыпалась в противень и взвешивалась, после чего высушивалась до постоянной массы. Влажность песка $(W)$ в процентах вычислялась по формуле (1): 


$$
W=\frac{m-m_{1}}{m_{1}} \times 100,
$$

где $m$ - масса навески в состоянии естественной влажности; $m_{1}$ - масса навески в сухом состоянии, г.

Установка поливинилхлоридной трубы диметром 10 см под углом $30^{\circ}$ в бункер Installation of plastic pipe with a diameter of $10 \mathrm{~cm}$ at the angle of $30^{\circ}$ into the bunker

Послойное заполнение трубы песчаным водонасыщенным грунтом с последующим трамбованием Layer-by-layer tube filling with sandy water-saturated soil, followed by compaction

Извлечение поливинилхлоридной трубы с образованием направляющей скважины для последующего устройства экрана

Removing the plastic pipe with the formation of a pilot hole for the subsequent arrangement of the shield

Разработка грунта в направляющей скважине при вращении с одновременным поступательным движением шнека

Development of soil in a pilot hole while rotating the auger with simultaneous progressive movement

\begin{tabular}{|c|} 
Подача раствора при обратном вращении шнека \\
Solution supply with reverse rotation of the auger \\
$\begin{array}{c}\text { Изъятие затвердевшего образца экрана из бункера с последующим распиливанием } \\
\text { Removal of the hardened sample of the shield from the bunker, followed by sawing }\end{array}$ \\
\hline $\begin{array}{c}\text { Визуальный осмотр и проведение испытаний образцов } \\
\text { Visual inspecting and testing of samples }\end{array}$ \\
\hline
\end{tabular}

Pис. 2. Методика проведения экспериментальных исследований в лабораторном стенде

Fig. 2. Method for conducting experimental research in a laboratory bench

Изготовление образцов осуществлялось в бункере лабораторного стенда с помощью подвижного шнека. В качестве привода для вращения однонаправленной части шнека использовался шуруповерт и перфоратор Поверхность образцов очищалась от пыли, грязи и следов смазки с помощью проволочной щетки. Эталонные образцы испытывались высушенными до постоянной массы, после чего они помещались в сосуд, наполненный водой с таким расчетом, чтобы уровень воды в нём был выше верхнего уровня образцов примерно на 50 мм. Образцы следует класть на прокладки так, чтобы их высота была минимальной. Температура воды в сосуде была $(20 \pm 2){ }^{\circ} \mathrm{C}$. Образцы взвешивались каждые 24 часа нахождения в воде на весах для гидростатического взвешивания. Испытания проводились до тех пор, пока два последовательных взвешивания не отличались более чем на $0,1 \%$.

Оценка пластической прочности растворных композиций проводилась на пластометре Ребиндера, модернизированном электроприводом.

Испытания скорости разработки грунта выполнялось следующим образом. Производилась разработка грунта в направляющей скважине при вращении шнека против часовой стрелки. Мощность колебалась от 245 до 560 Вт, соответственно, при низкой и высокой скорости вращения (разработка под собственным весом шнека). Вращение шнека производилось при трех скоростях привода - высокой (1,5 об/с, или 90 об/мин), средней (1 об/с, или 60 об/мин) и низкой $(0,5$ об/с, или 30 об/мин). При вращении шнека со скоростью выше 2 об/с наблюдались вибрации и обрывы грунта, в связи с этим не рекомендуется превышать данную частоту вращения. Разработка производится под собственным весом шнека - 3,2 кг. В процессе разработки грунта секундомером замерялось время прохождения шнеком 1 метра грунта при непрерывной разработке по оси шнека вдоль направляющей скважины.

Для испытания скорости бетонирования производилась подача раствора с одновременным вращением шнека по часовой стрелке. Для определения скорости бетонирования при различных скоростях вращения шнека (высокой, средней и низкой) засекалось время перемешивания грунта и раствора на одной стоянке шнека. Стоянки производились каждые 5 см (половина диаметра шнека) для тщательного перемешивания подаваемого раствора и грунта до образования однородной массы. Скорость бетонирования в настоящем исследовании равна отношению метра погонного 
направляющей скважины по оси шнека к времени перемешивания одной стоянки. Для изменения скорости разработки грунта при низкой частоте вращения шнека прикладывался дополнительный вес (тянущее усилие) с обеих сторон бункера к валу шнека. Тянущее усилие прикладывалось вдоль направляющей скважины грузами по направляющим и с помощью электронного динамометра. Величина усилия составляет от 31,36 до 50,96 Н. В связи с тем, что груз дает увеличение скорости разработки за счет большего врезания лопастей, а при 50,96 Н врезание лопастей достигло максимума, применение тянущего усилия свыше 50,96 Н не является целесообразным.

Для получения образцов в качестве основы экрана выбран цементно-песчаный раствор в соотношении 1:3, водоцементное отношение равно 1. Для придания экрану водонепроницаемых и прочностных свойств вводились добавки. Гидрофобизирующая добавка вводилась в равном количестве во все исследуемые образцы - 0,1%. В помещении лаборатории температура составляла $21{ }^{\circ} \mathrm{C}$, влажность 65 \%. Были выбраны следующие гидрофобные и армирующие материалы для устройства противофильтрационного экрана.

- бентонит как вещество, обладающее наиболее выраженными гидрофобными свойствами;

- жидкое стекло, которое проникает в самые мелкие трещинки и поры, хорошо укрепляет бетонные и деревянные основания, создает водонепроницаемую пленку;

- пластификатор препятствует расслоению растворной смеси и, как следствие, предотвращает потерю гидрофобных свойств состава;

- стекловолокнистая фибра, повышающая связывающие характеристики раствора и позволяющая равномерно выполнять армирование конструкции, препятствует образованию микротрещин;

- гидрофобная добавка, которая уменьшает водопоглощение, увеличивает прочность на сжатие и изгиб при растяжении, повышает стойкость в агрессивной среде.

Для бетонирования применялись литые бетоны с осадкой конуса 16-20 см, со сроком схватывания не менее 2 ч, с сохранением подвижности в течение 40 мин и крупностью заполнителя не более 30 мм. Для получения бетонов требуемых технологических параметров (повышенной подвижности, связности и замедленного схватывания) вводились химические добавки.

Обработка результатов экспериментов выполнялась с помощью методов корреляционно-регрессионного анализа в диалоговой системе CompEx. В ходе анализа проверялись гипотезы о равности настоящих коэффициентов экспериментально-статистической модели, а также про адекватность модели экспериментальным данным, по которым она построена. Критерий Стьюдента (t-критерий) выбирался для заданного уровня риска $(\alpha=0,2)$ и заданного числа степеней свободы эксперимента. Модель проверялась на адекватность с использованием информации про среднеквадратическую ошибку эксперимента, $\mathrm{S}_{\mathrm{E}}$, и среднеквад- ратическую ошибку неадекватности, $\mathrm{S}_{\mathrm{HA}}$. Проверка по критерию Фишера выполнялась при $\beta=0,05$. Построенные экспериментально-статистические модели удовлетворяли двум гипотезам: все оценки коэффициентов значимые (с заданным уровнем риска $\alpha$ ) и отличаются от нуля. Так как использовались разные факторы и уровни их варьирования, для каждого эксперимента принимались собственные планы экспериментов, описанные в соответствующих разделах, и экспериментально-статистические модели, общий вид которой показан в формуле (2).

$$
\begin{gathered}
Y=b_{0}+\sum_{i=1}^{k} b_{i} x_{i}+\sum_{i=1}^{k} b_{i j} x_{i} x_{j}+\sum_{i=1}^{k} b_{i i} x_{i}^{2}+ \\
+\sum_{i=1}^{k} b_{j j} x_{j}^{2}+\cdots+\varepsilon .
\end{gathered}
$$

\section{Исследование скорости разработки грунта при изменении угловой скорости вращения шнека и тягового усилия}

Были выбраны следующие факторы для исследования показателя «скорость разработки грунта»: $\mathrm{X}_{1}$ угловая скорость: $0,5,1$ и $1,5 \mathrm{c}^{-1} ; \mathrm{X}_{2}$ - тяговое усилие: 31,36, 41,16, 50,96 Н. Серия опытных образцов выполнялась на лабораторном стенде согласно сокращенному плану эксперимента с девятью наблюдениями. План эксперимента, уровни варьируемых технологических параметров и результаты показаны в табл. 1.

По результатам расчёта в программном комплексе CompEx была получена следующая экспериментально-статистическая модель показателя «скорость разработки грунта» (3). Ошибка эксперимента составила $\mathrm{S}_{3}=0,129$ м/ч. Коэффициенты, признанные неотличимыми от нуля, исключены из модели.

$$
\begin{gathered}
\text { Скорость разработки грунта } Y_{1}(\text { м/ч })=11,170+ \\
+3,727 X_{1}+0,483 X_{1}^{2}++0,345 X_{1} X_{2}+0,990 X_{2} .
\end{gathered}
$$

Таблица 1. План и результаты эксперимента по определению влияния технологических факторов на скорость разработки грунта

\begin{tabular}{|c|c|c|c|c|}
\hline \multicolumn{4}{|c|}{ Значения факторов/Factor values } & \multirow{3}{*}{$\begin{array}{c}\text { Скорость разра- } \\
\text { ботки грунта } \\
\mathrm{Y}_{1, \mathrm{M}} / \mathrm{u} \\
\text { Speed of } \\
\text { concreting } \mathrm{Y}_{1} \text {, } \\
\mathrm{m} / \mathrm{h}\end{array}$} \\
\hline \multicolumn{2}{|c|}{ Натурные/Natural } & \multicolumn{2}{|c|}{$\begin{array}{c}\text { Нормализован- } \\
\text { ные } \\
\text { Normalized } \\
\end{array}$} & \\
\hline $\begin{array}{l}\text { Угловая ско- } \\
\text { рость } \mathrm{X}_{1}, \mathrm{c}^{-1} \\
\text { Angular } \\
\text { speed } \mathrm{X}_{1}, \mathrm{c}^{-1}\end{array}$ & $\begin{array}{c}\text { Тяговое } \\
\text { усилие } \mathrm{X}_{2}, \mathrm{H} \\
\text { Pulling force } \\
\mathrm{X}_{2}, \mathrm{~N}\end{array}$ & $\mathrm{X}_{1}$ & $\mathrm{X}_{2}$ & \\
\hline 0,5 & 31,36 & -1 & -1 & 7,28 \\
\hline 0,5 & 41,16 & -1 & 0 & 7,89 \\
\hline 0,5 & 50,96 & -1 & 1 & 8,69 \\
\hline 1 & 31,36 & 0 & -1 & 10,34 \\
\hline 1 & 41,16 & 0 & 0 & 11,25 \\
\hline 1 & 50,96 & 0 & 1 & 11,92 \\
\hline 1,5 & 31,36 & 1 & -1 & 14,01 \\
\hline 1,5 & 41,16 & 1 & 0 & 15,25 \\
\hline 1,5 & 50,96 & 1 & 1 & 16,72 \\
\hline
\end{tabular}

Table 1. Plan and results of the experiment to determine the influence of technological factors on concreting speed

Рассмотрим ранжирование степени влияния варьируемых факторов на показатель (рис. 3). Отметим высокое влияние угловой скорости на скорость разработки грунта. При этом влияние тягового усилия 
ниже и равно 32 \% в зоне максимума, которая является более значимой в рамках настоящего исследования.

На рис. 4 показаны однофакторные зависимости скорости разработки грунта $\mathrm{Y}_{1}$ от угловой скорости $\mathrm{X}_{1}$ и тягового усилия $\mathrm{X}_{2}$. В зоне максимумов и минимумов характер влияния обоих факторов имеет прямо пропорциональную зависимость. В данном исследовании ценность представляют значения в зоне максимумов, которые позволяют быстрее производить разработку грунта. В зоне максимумов наибольшая скорость разработки грунта достигается при угловой скорости 1,5 $\mathrm{c}^{-1}$ и тяговом усилии $50,96 \mathrm{H}$.

Рассмотрим изолинии изменения показателя скорости разработки грунта $\mathrm{Y}_{1}$ от двух факторов: «угловая скорость» $\mathrm{X}_{1}$ и «тяговое усилие» $\mathrm{X}_{2}$ (рис. 5). Максимальное значение скорости разработки грунта, равное 16,72 м/ч, наблюдается при угловой скорости $1,5 \mathrm{c}^{-1}$, тяговом усилии 50,96 Н. Минимум полученной ЭС-модели находится в точке $\left(\mathrm{X}_{1}=0,5 \mathrm{c}^{-1}\right.$; $\left.\mathrm{X}_{2}=31,36 \mathrm{H}\right)$. Наиболее рациональным является сочетание уровней факторов в точке максимума показателя. Дальнейшее увеличение скорости и тягового усилия является нецелесообразным. Причинами являются следующие: при тяговом усилии $50,96 \mathrm{H}$ врезание лопастей достигает максимума; при большей скорости вращения (более $1,5 \mathrm{c}^{-1}$ ) наблюдались сильные вибрации и обвалы грунта.

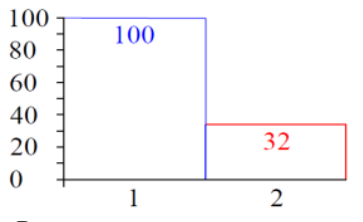

Ранжирование по максимуму Ranking in the maximum zone

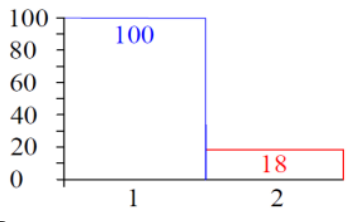

Ранжирование по минимуму Ranking in the minimum zone
Pис. 3. Ранжирование влияния варьируемых факторов на показатель скорости разработки грунта $Y_{l}$ (номерами показаны индексы факторов: угловая скорость $X_{1}$, тяговое усилие $X_{2}$ )

Fig. 3. Ranking of the influence of variable factors on concreting speed $Y_{1}$ (the numbers show the factor indices: angular speed $X_{1}$, pulling force $X_{2}$ )
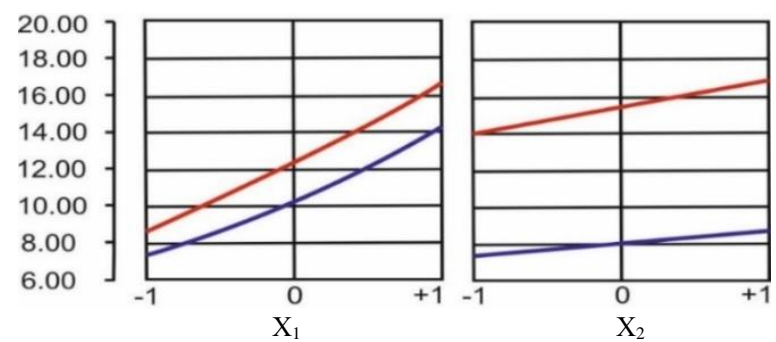

Рис. 4. Графики зависимости показателя скорости разработки грунта $Y_{1}$ от каждого из факторов: угловая скорость $X_{1}, c^{-1}$, и тяговое усилие $X_{2}, H$ (верхняя линия - влияние в зоне максимума, нижняя - в зоне минимума показателя)

Fig. 4. Graphs of the concreting speed $Y_{1}$ dependence on each of the factors: angular speed $X_{1}, s^{-1}$, and pulling force $X_{2}, N$ (the upper line is the dependence in the maximum zone, the lower one is in the minimum zone of the indicator)

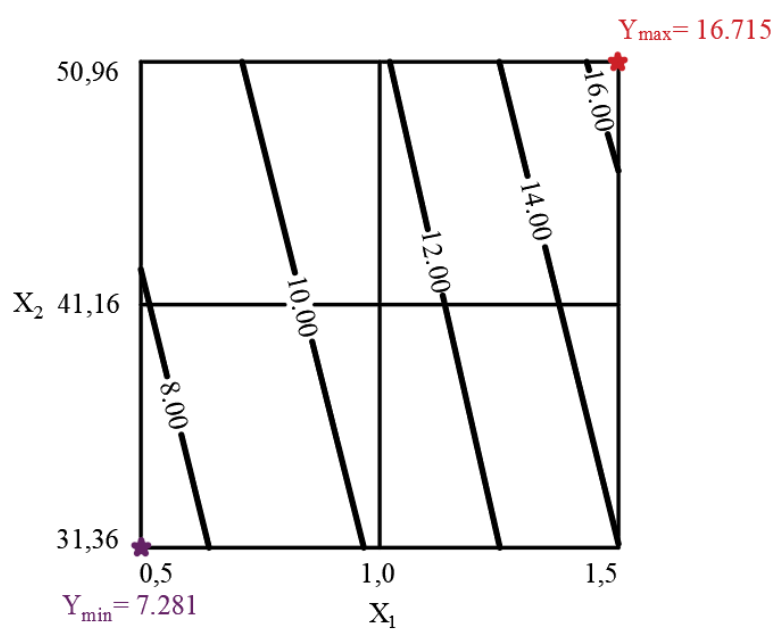

Puc. 5. Совместное влияние угловой скорости $X_{1}, c^{-1}, u$ тягового усилия $X_{2}, H$, на скорость разработки грунта $Y_{1}(\mathrm{M} / \mathrm{u})$

Fig. 5. Influence of the angular speed $X_{1}, s^{-1}$, and pulling force $X_{2}, N$, on the concreting speed $Y_{1}(\mathrm{~m} / \mathrm{h})$

\section{Исследование скорости бетонирования при изменении производительности подачи состава в полость экрана и угловой скорости вращения шнека}

Были выбраны следующие факторы для исследования показателя «скорость бетонирования»: $\mathrm{X}_{1}-$ угловая скорость: $0,5,1$ и $1,5 \mathrm{c}^{-1} ; \mathrm{X}_{2}$ - производительность подачи раствора: $30,40,50 \mathrm{~m}^{3} /$ ч. Серия опытных образцов выполнялась на лабораторном стенде согласно сокращенному плану эксперимента с девятью наблюдениями. План эксперимента, уровни варьируемых технологических параметров и результаты показаны в табл. 2 .

По результатам расчёта в программном комплексе CompEx была получена следующая экспериментально-статистическая модель показателя «скорость бетонирования» (4). Ошибка эксперимента составила $\mathrm{S}_{3}=0,061 \mathrm{~m} /$ ч. Коэффициенты, признанные неотличимыми от нуля, исключены из модели.

Скорость бетонирования $Y_{2}$ (м/ч) $=8,520+$

$+2,340 X_{1}-0,180 X_{1}^{2}++0,395 X_{2}-0,145 X_{2}^{2}$.

Рассмотрим ранжирование степени влияния варьируемых факторов на показатель (рис. 6). Отметим высокое влияние угловой скорости $\mathrm{X}_{1}$ на скорость бетонирования $\mathrm{Y}_{2}$. При проведении экспериментальных исследований этот факт был в значительной степени очевиден, так как требовалось некоторое время, на протяжении которого производилось перемешивание грунта с раствором на каждой стоянке до образования однородного грунтобетонного экрана. При этом влияние производительности подачи раствора $\mathrm{X}_{2}$ значительно ниже и равно $16 \%$ в зоне максимума и минимума.

На рис. 7 показаны однофакторные зависимости скорости бетонирования $\mathrm{Y}_{2}$ от угловой скорости $\mathrm{X}_{1}$ и производительности подачи раствора $\mathrm{X}_{2}$. В зоне максимумов и минимумов характер влияния обоих показателей имеет прямо пропорциональную зависимость. В данном исследовании ценность представляют значения как в зоне максимумов, так и в зоне минимумов. 
В зоне максимумов наибольшая скорость бетонирования достигается при значении факторов «угловая скорость» $\mathrm{X}_{1}=1,5 \mathrm{c}^{-1}$ и «производительность подачи раствора» $\mathrm{X}_{2}=50 \mathrm{~m}^{3} /$ ч. В зоне минимумов наименьшая медленная скорость бетонирования достигается при значении факторов «угловая скорость» $\mathrm{X}_{1}=0,5 \mathrm{c}^{-1}$ и «производительность подачи раствора» $\mathrm{X}_{2}=30 \mathrm{~m}^{3} /$ ч

Рассмотрим изолинии изменения показателя «скорость бетонирования» $\mathrm{Y}_{2}$ от двух факторов: «угловая скорость» $\mathrm{X}_{1}, \mathrm{c}^{-1}$, и «производительность подачи раствора» $\mathrm{X}_{2}, \mathrm{M}^{3} /$ ч (рис. 8). Максимальное значение скорости бетонирования, равное $\mathrm{Y}_{2}=10,93 \mathrm{M} / 4$, наблюдается при угловой скорости $\mathrm{X}_{1}=1,5 \mathrm{c}^{-1}$ и производительности подачи состава $\mathrm{X}_{2}=50 \mathrm{~m}^{3} /$. Минимум скорости бетонирования находится в точке $\left(\mathrm{X}_{1}=0,5 \mathrm{c}^{-1}\right.$; $\mathrm{X}_{2}=30 \mathrm{~m}^{3} /$ ч) и равен $\mathrm{Y}_{2}=5,46 \mathrm{~m} /$. Дальнейшее увеличение угловой скорости является нецелесообразным, так как при большей скорости вращения (более 1,5 об/с) наблюдались сильные вибрации и обвалы грунта.

Таблица 2. План и результать эксперимента по определению влияния технологических факторов на скорость разработки грунта

Table 2. $\quad$ Plan and results of experiment to determine the influence of technological factors on concreting speed

\begin{tabular}{|c|c|c|c|c|}
\hline \multicolumn{4}{|c|}{ Значения факторов/Factor values } & \multirow{3}{*}{$\begin{array}{c}\text { Скорость } \\
\text { бетонирова- } \\
\text { ния } \mathrm{Y}_{2}, \mathrm{M} / \mathrm{ч} \\
\text { Speed of } \\
\text { concreting } \\
\mathrm{Y}_{2}, \mathrm{~m} / \mathrm{h}\end{array}$} \\
\hline \multicolumn{2}{|c|}{ Натурные/Natural } & \multicolumn{2}{|c|}{\begin{tabular}{|l} 
Нормали- \\
зованные \\
Normalized
\end{tabular}} & \\
\hline $\begin{array}{c}\text { Угловая ско- } \\
\text { рость } \mathrm{X}_{1}, \mathrm{c}^{-1} \\
\text { Angular speed } \\
\mathrm{X}_{1}, \mathrm{~s}^{-1} \\
\end{array}$ & \begin{tabular}{|c|} 
Производительность \\
подачи раствора $\mathrm{X}_{2}, \mathrm{~m}^{3} / \mathrm{ч}$ \\
Feed rate of the solution \\
$\mathrm{X}_{2}, \mathrm{~m}^{3} / \mathrm{h}$ \\
\end{tabular} & $X_{1}$ & $\mathrm{X}_{2}$ & \\
\hline 0,5 & 30 & -1 & -1 & 5,46 \\
\hline 0,5 & 40 & -1 & 0 & 5,97 \\
\hline 0,5 & 50 & -1 & 1 & 6,24 \\
\hline 1 & 30 & 0 & -1 & 7,86 \\
\hline 1 & 40 & 0 & 0 & 8,60 \\
\hline 1 & 50 & 0 & 1 & 8,81 \\
\hline 1,5 & 30 & 1 & -1 & 10,22 \\
\hline 1,5 & 40 & 1 & 0 & 10,63 \\
\hline 1,5 & 50 & 1 & 1 & 10,93 \\
\hline
\end{tabular}

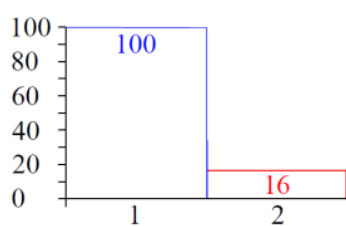

Ранжирование по максимуму Ranking in the maximum zone

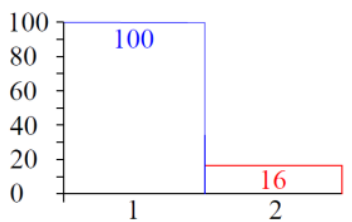

Ранжирование по минимуму Ranking in the minimum zone
Pис. 6. Ранжирование влияния варьируемых факторов на показатель скорости бетонирования $Y_{2}$ (номерами показань индексы факторов: угловая скорость $X_{1}$, производительность подачи расmвора $X_{2}$ )

Fig. 6. Ranking of the variable factors influence on concreting speed $Y_{2}$ (the numbers show the factor indices: angular speed $X_{1}$, feed rate of the solution $X_{2}$ )

Полученные данные позволяют определять скорость бетонирования для различных по ширине зда- ний. Для небольших по ширине сооружений (10-20 м) при применении быстротвердеющих составов с быстрым набором пластической прочности допускается медленное бетонирование со скоростью 5-6 м/ч. Для сооружений большой ширины (40-60 м) подходят составы с минимальной пластической прочностью, при этом скорость бетонирования должна быть максимальной $(10-11$ м/ч).
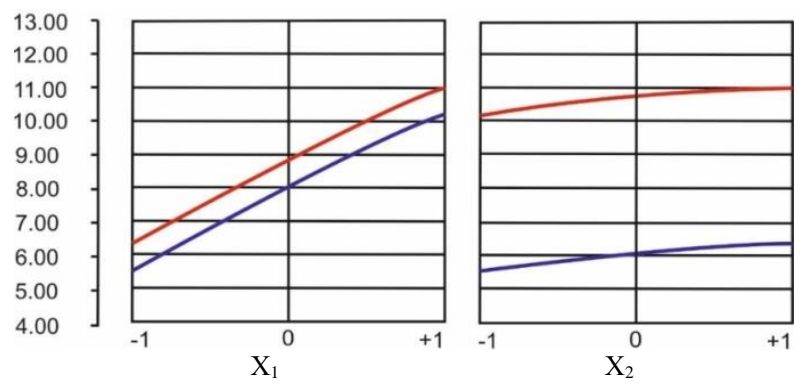

Puc. 7. Графики зависимости показателя скорости бетонирования $Y_{2}$ от каждого из факторов: угловая скорость $X_{1}, c^{-1}$, и производительность подачи раствора $X_{2}, м^{3} / 4$ (верхняя линия - влияние в зоне максимума, нижняя - в зоне минимума показателя)

Fig. 7. Graphs of concreting rate of $Y_{2}$ dependence on each of the factors: angular speed $X_{1}, s^{-1}$, and the feed rate of the solution $X_{2}, \mathrm{~m}^{3} / \mathrm{h}$ (the upper line is the dependence in the maximum zone, the lower one is in the minimum zone of the indicator)

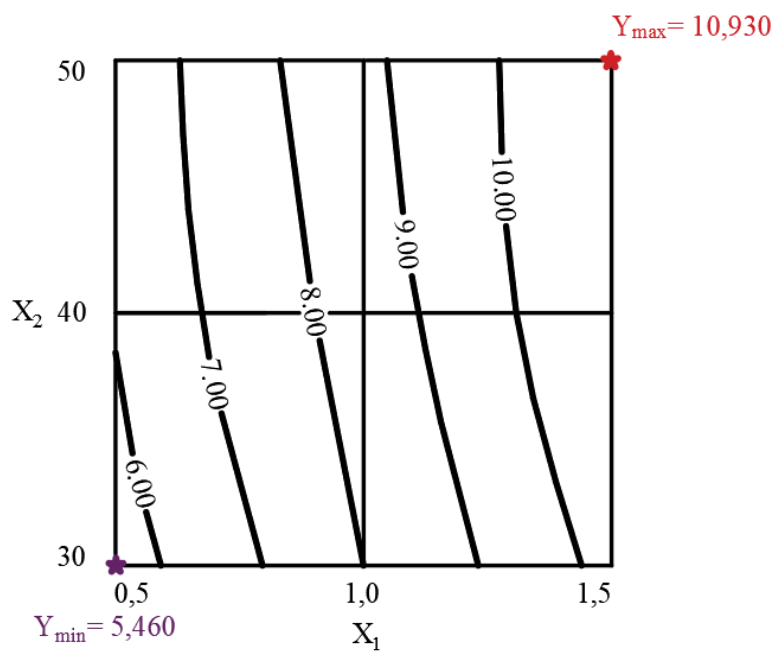

Pис. 8. Совместное влияние угловой скорости $X_{1}, c^{-1}, u$ производительности подачи раствора $X_{2}, м^{3} / 4$, на скорость бетонирования $Y_{2}(\mathrm{M} / \mathrm{u})$

Fig. 8. Influence of the angular speed $X_{1}, s^{-1}$, and the feed rate of the solution $X_{2}, \mathrm{~m}^{3} / \mathrm{h}$, on the concreting speed $Y_{2}(\mathrm{~m} / \mathrm{h})$

\section{Применение шнековой технологии устройства противофильтрационного экрана для обеспечения радиационной безопасности}

Настоящие рекомендации разработаны для применения шнековой технологии устройства противофильтрационных экранов под различными сооружениями, представляющими экологическую опасность: могильниками радиоактивных отходов, зонами раз- 
лива нефтепродуктов и других токсичных веществ и другими опасными сооружениями. Также возможно применение технологии для защиты территорий от подтопления подземными водами, защиты каналов и водохранилищ от подземного загрязнения.

Концепция использования шнековой технологии следующая. Бурение технологических скважин производится в шахматном порядке и в два этапа с минимальным воздействием на фундамент существующего здания (рис. 9). На первом этапе скважины бурятся криволинейно, аутентично подошве существующего здания или сооружения. Требуемый наклон скважин определяется с учетом глубины заложения фундамента и ширины участка, возможной для отведения под защитные работы. Шаг скважин зависит от ширины сооружения и геологических условий устройства противофильтрационного экрана и изменяется в пределах от 1 до 2 м. Глубина технологических скважин определяется с учетом пересечения двух противоположных плоскостей в нижнем уровне противофильтрационного экрана и их взаимного сопряжения. Расположение скважин двух плоскостей относительно друг друга целесообразно выполнять с перевязкой для обеспечения их сопряжения при пересечении.

После достижения глубины бурения формируется прорезь при вымывании грунта, выбуриваемого шнеком. Одновременно к шнеку через штанги подается твердеющий раствор, который при обратной проходке (рис. 10) заполняет прорезь. Буровая установка равномерно поднимает вращающийся шнек с помощью направляющих штанг. Гидравлический двигатель вращает шнек, который прикреплен к штангам буровой установки.

Противофильтрационные экраны образуются за счет пересекающихся панелей, получаемых в результате перемешивания грунта основания с твердеющими растворами. По торцам противофильтрационный экран устраивается с помощью вертикальных экранов, которые сопряжены с криволинейными плоскостями, описанными выше (рис. 11). Вертикальные экраны завершают создание сплошного противофильтрационного экрана, который приобретает вид призмы.

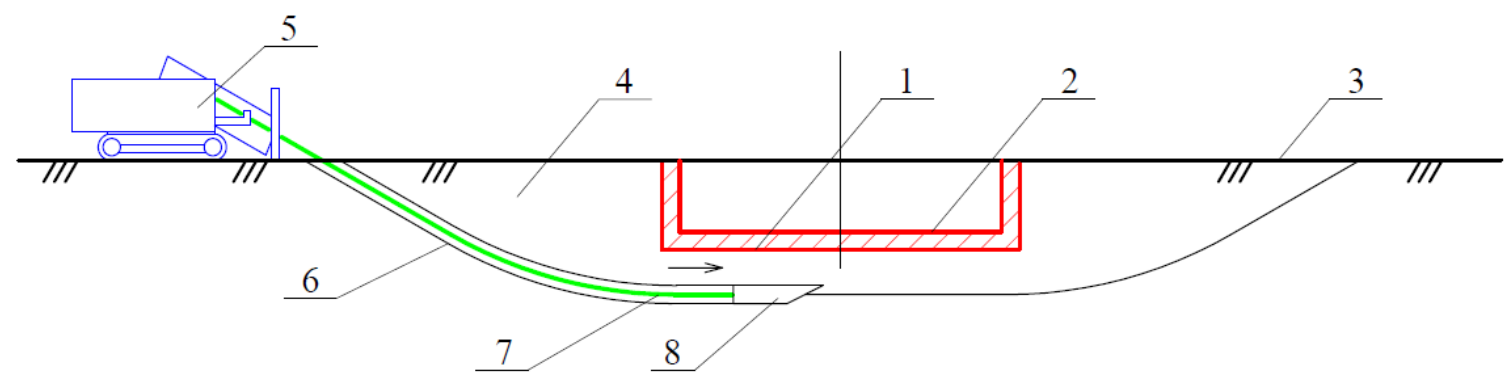

Pис. 9. Разрез устройства противофильтрационного экрана с помощью шнековой технологии: бурение направляющих скважин (1 - объект защиты; 2 - подошва сооружения; 3 - поверхность грунта; 4 - грунт; 5 - буровая установка; 6 - направляющая скважина; 7 - проходческая жидкость; 8 -бур)

Fig. 9. Section of the anti-filtration shield arrangement using auger technology: drilling pilot wells (1 - protected structure; 2 - base of the structure; 3 - soil surface; 4 -soil; 5 -drilling rig; 6 -pilot well; 7 -tunneling fluid; 8 -borer)

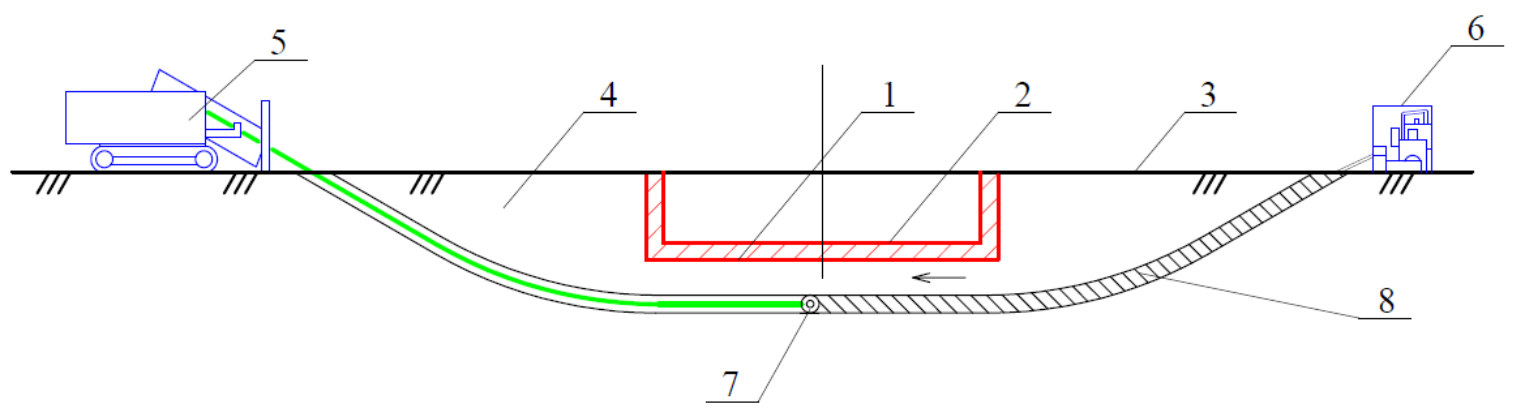

Pис. 10. Разрез устройства противофильтрачионного экрана с помощью шнековой технологии: нагнетание закрепляюшего раствора (1 - объект защиты; 2 - подошва сооружения; 3 - поверхность грунта; 4 - грунт; 5 - буровая установка; 6 - миксерная станщия; 7 - двунаправленный шнек; 8 - раствор)

Fig. 10. Section of the anti-filtration shield arrangement using auger technology: injection of a solution (1 - protected structure; 2 -base of the structure; 3 - soil surface; 4 -soil; 5 -drilling rig; 6 - mixing station; 7 -bi-directional auger; 8 - solution)

Расчет требуемого объема бурового раствора для одной скважины можно определить по формуле (5):

$$
V_{\text {б.р. }}=D_{\text {скв. }} \times L_{\text {скв. }} \times K_{\text {p. }}
$$

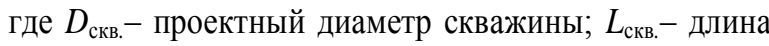
скважины; $K_{\mathrm{p}}-$ коэффициент расхода бурового раствора.
Расчет требуемого объема инъецируемого раствора определяется по формуле (6):

$$
V_{\text {и.р. }}=S_{\text {уч. }} \times L_{\text {скв. }}+\times S_{\text {скв. }} \times L_{\text {скв. }}
$$

где $S_{\text {уч. }}$ - площадь поперечного сечения участка; $L_{\text {скв. }}$ - длина скважины; $S_{\text {скв }}$ - площадь поперечного сечения скважины. 


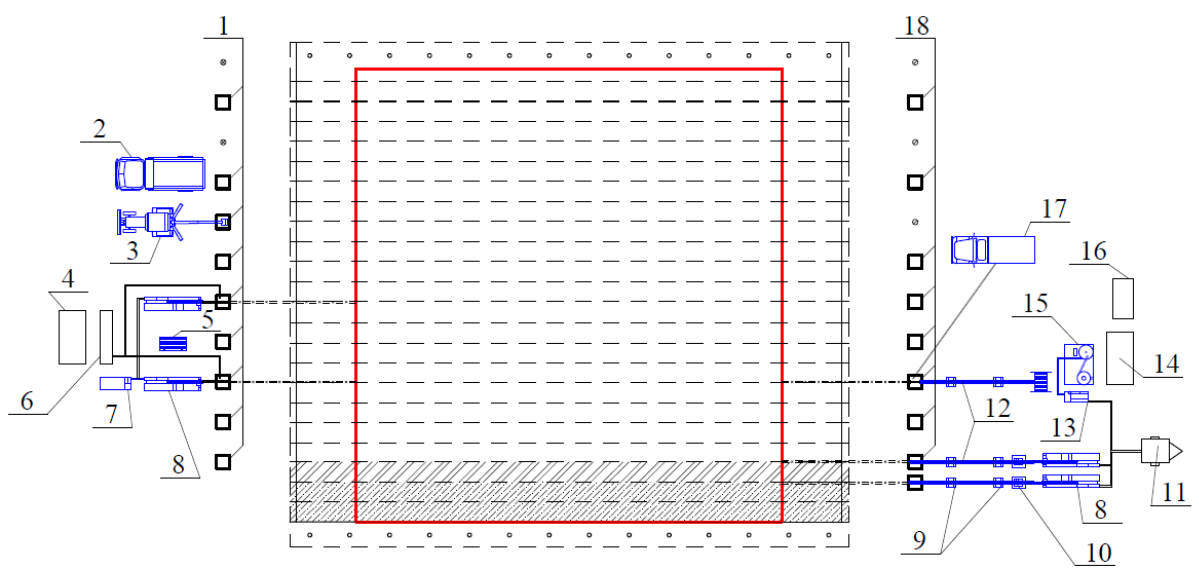

Рис. 11. План-схема устройства противофильтрационного экрана с помощью шнековой технологии (1 - приямок бурового входа; 2 - автосамосвал; 3 - экскаватор-бульдозер; 4 - склад бентонита; 5 - склад гибких буровых штанг; 6 - блок очистки бурового раствора; 7 - установка для подготовки бурового раствора; 8 - установка для горизонтально направленного бурения; 9 - роликовая подставка; 10 - лебедка с редуктором; 11 компрессор; 12 - подводящие шланги; 13 -насос; 14 - склад иемента; 15 -миксерная станция для раствора; 16 - генератор; 17 - илосос; 18 - выходной приямок)

Fig. 11. Schematic diagram of the arrangement of an anti-filtration shield using auger technology ( 1 - pit of the drilling entrance; 2 -dump truck; 3 -excavator; 4 - bentonite storage; 5 -flexible drill rods storage; 6 -drilling mud cleaning unit; 7 - machine for drilling mud preparation; 8 - machine for horizontal directional drilling; 9 - roller stand; 10 - winch with a gearbox; 11 - compressor; 12 - supply hoses; 13 - pump; 14 - cement storage; 15 - mixing station for solution; 16 - generator; 17 - sludge pump; 18 - outlet pit)

Необходимые операции для устройства противофильтрационного экрана для обеспечения радиационной безопасности, а также затраты труда и машинного времени на них показаны в табл. 3. В связи с от- сутствием в современной нормативной базе норм на выполнение операций с установками горизонтально направленного бурения соответствующие нормы времени приняты по результатам экспертной оценки.

Таблица 3. Затраты труда и машинного времени на операции для устройства противофильтрационного экрана

Table 3. Labor and machine time spent on operations for anti-filtration shields arrangement

\begin{tabular}{|c|c|c|c|c|}
\hline $\begin{array}{l}\text { Обоснование } \\
\text { нормы } \\
\text { Identifier of } \\
\text { normative } \\
\text { document }\end{array}$ & $\begin{array}{l}\text { Наименование работы } \\
\text { Name of work }\end{array}$ & $\begin{array}{l}\text { Ед. изм. } \\
\text { Unit }\end{array}$ & $\begin{array}{c}\text { Норма времени } \\
\text { на ед. изм. } \\
\text { чел.-ч./маш.-ч. } \\
\text { Time for unit } \\
\text { hours (labor)/ } \\
\text { hours (machine) }\end{array}$ & $\begin{array}{c}\text { Состав звена по норме } \\
\text { Team content }\end{array}$ \\
\hline E2-1-9 & $\begin{array}{c}\text { Устройство приямков экскаватором } \\
\text { Pit excavation }\end{array}$ & $100 \mathrm{~m}^{3} / \mathrm{m}^{3}$ & $2,7 / 2,7$ & $\begin{array}{c}\text { Машинист } 5 \text { p. (Machinist) - } 1 \\
\text { Экскаватор ЭО-2621 } \\
\text { (Excavator EO-2621)-1 }\end{array}$ \\
\hline E14-23 & $\begin{array}{l}\text { Приготовление и очистка бурового раствора } \\
\text { Preparation and cleaning of drilling mud }\end{array}$ & $10 \mathrm{~m}^{3} / \mathrm{m}^{3}$ & $1,68 / 0,42$ & $\begin{array}{l}\text { Машинист } 5 \text { p. (Machinist) - } 1 \\
\text { Помощник машиниста } 3 \text { p. } \\
\text { (Machinist assistant) }-2 \\
\text { HP-300 (Vermeer HP-300) }-1\end{array}$ \\
\hline \multirow{4}{*}{ 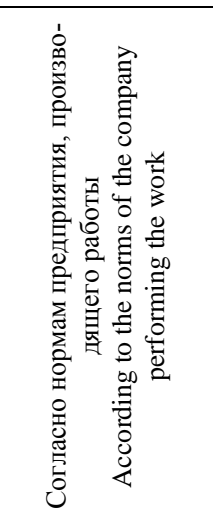 } & $\begin{array}{c}\text { Бурение пилотной скважины, расширение и } \\
\text { затягивание струйного монитора, передвиже- } \\
\text { ние и монтаж буровой установки } \\
\text { Drilling a pilot well, expanding and tightening the } \\
\text { jet monitor, moving and installing the drilling rig }\end{array}$ & $\begin{array}{l}1 \text { м. п. скв. } \\
1 \mathrm{~m} \text { of well }\end{array}$ & $0,40 / 0,20$ & $\begin{array}{c}\text { Машинист } 6 \text { p. (Machinist) - } 2 \\
\text { Цементатор } 5 \text { p. (Cementator) - } 1 \\
\text { Цементатор } 4 \text { p. (Cementator) }-1 \\
\text { Vermeer Navigator } \\
\text { (Vermeer Navigator HP-300) }-1\end{array}$ \\
\hline & $\begin{array}{c}\text { Устройство горизонтального противофильтра- } \\
\text { ционного экрана } \\
\text { Horizontal anti-filtration shield arrangement }\end{array}$ & $\begin{array}{c}1 \text { м. п. } \\
\text { участка } \\
1 \mathrm{~m} \text { of site }\end{array}$ & $0,32 / 0,08$ & $\begin{array}{c}\text { Машинист } 5 \text { p. (Machinist) }-1 \\
\text { Машинист } 4 \text { p. (Machinist) }-1 \\
\text { Цементатор } 5 \text { p. (Cementator) }-1 \\
\text { Цементатор } 4 \text { p. (Cementator) }-1\end{array}$ \\
\hline & $\begin{array}{c}\text { Устройство вертикального противофильтраци- } \\
\text { онного экрана } \\
\text { Vertical anti-filtration screen arrangement }\end{array}$ & $\begin{array}{c}1 \text { м. п. } \\
\text { участка } \\
1 \text { m of site }\end{array}$ & $0,28 / 0,06$ & $\begin{array}{c}\text { Машинист } 5 \text { p. (Machinist) }-1 \\
\text { Машинист } 4 \text { p. (Machinist) }-1 \\
\text { Цементатор } 5 \text { p. (Cementator) }-1 \\
\text { Цементатор } 4 \text { p. (Cementator) }-1\end{array}$ \\
\hline & $\begin{array}{c}\text { Откачка буровой пульпы из приямка } \\
\text { Pumping drill slurry out of pit }\end{array}$ & $\begin{array}{l}1 \text { м. п. скв. } \\
1 \mathrm{~m} \text { of well }\end{array}$ & $0,16 / 0,14$ & $\begin{array}{c}\text { Машинист } 5 \text { p. (Machinist) - } 1 \\
\text { Помощник машиниста } 3 \text { p. } \\
\text { (Machinist assistant) }-1\end{array}$ \\
\hline $\begin{array}{c}\text { E4-1-47, п.4а } \\
\text { (применительно, } \\
\text { applicable) }\end{array}$ & $\begin{array}{l}\text { Приготовление инъекционного раствора } \\
\text { Preparation of injection solution }\end{array}$ & $1 \mathrm{~m}^{3} / \mathrm{m}^{3}$ & $0,25 / 0,00$ & $\begin{array}{l}\text { Машинист } 4 \text { р. (Machinist) - } 1 \\
\text { Миксерная станция CM-40/90 } \\
\text { (Mixer station SM-40/90) - } 1\end{array}$ \\
\hline E2-1-22 & $\begin{array}{l}\text { Засыпка приямков бульдозером } \\
\text { Backfilling of pits with a bulldozer }\end{array}$ & $100 \mathrm{~m}^{3} / \mathrm{m}^{3}$ & $0,8 / 0,8$ & $\begin{array}{c}\text { Машинист } 5 \text { p. (Machinist) - } 1 \\
\text { Бульдозер Д-104 } \\
\text { (Bulldozer D-104) - 1 }\end{array}$ \\
\hline
\end{tabular}


Разработанные технологические приёмы, а также таблица, позволяют использовать новую технологию для обеспечения радиационной безопасности путём эффективной защиты зданий и сооружений от подземных вод, а подземных вод - от загрязнения радиоактивными отходами.

\section{Выводы}

1. Данные по состоянию объектов захоронения радиоактивных отходов в Украине свидетельствуют, что актуальным является разработка экспериментального обоснования и устройства противофильтрационных экранов для препятствования распространению загрязненных радионуклидами подземных вод.

2. Максимальная скорость разработки грунта, равная 16,72 м/ч, наблюдается при угловой скорости $1,5 \mathrm{c}^{-1}$, тяговом усилии 50,96 Н. Дальнейшее увеличение скорости и тягового усилия является нецелесообразным. Причинами являются следующие: при тяговом усилии 50,96 Н врезание лопа-

\section{СПИСОК ЛИТЕРАТУРЬ}

1. Radionuclide migration at experimental polygon at Red Forest waste site in Chernobyl zone. P. 2: Hydrogeological characterization and groundwater transport modeling / D. Bugai, A. Skalskyy, S. Dzhepo, Y. Kubko, V. Kashparov, N. van Meir, A. Martin-Garin. - Applied Geochemistry. - 2012. - № 27 (7). P. 1359-1374. URL: https://doi.org/10.1016/j.apgeochem.2011.09.028 (дата обращения 28.12.2020).

2. High $36 \mathrm{Cl} / \mathrm{Cl}$ ratios in Chernobyl groundwater / C. Roux, C. le Gal La Salle, C. Simonucci, N. van Meir, L. Keith Fifield, O. Diez, J. Lancelot // Journal of Environmental Radioactivity. - 2014. № 138. - P. 19-32. URL: https://doi.org/10.1016/j.jenvrad. 2014.07.008 (дата обращения 28.12.2020).

3. Groundwater residence time downgradient of Trench No. 22 at the Chernobyl Pilot Site: Constraints on hydrogeological aquifer functioning / C. le Gal La Salle, L. Aquilina, E. Fourre, P. JeanBaptiste, J.-L. Michelot, C. Roux, J. Lancelot // Applied Geochemistry. - 2012. - № 27 (7). - P. 1304-1319. URL: https://doi.org/10.1016/j.apgeochem.2011.12.006 (дата обращения 28.12.2020)

4. Shcheglov A., Tsvetnova O., Klyashto A. Biogeochemical cycles of Chernobyl-born radionuclides in the contaminated forest ecosystems. Long-term dynamics of the migration processes // Journal of Geochemical Exploration. - 2014. - № 144 (B). P. 260-266. URL: https://doi.org/10.1016/j.gexplo.2014.05.026 (дата обращения 28.12.2020).

5. Jet grouting with a newly developed technology: The Twin-Jet method / Shui-Long Shen, Zhi-Feng Wang, Suksun Horpibulsuk, Yong-Hyun Kim // Engineering Geology. - 2013. - № 152 (1). P. 87-95. URL: https://doi.org/10.1016/j.enggeo.2012.10.018 (дата обращения 28.12.2020)

6. Makovetskiy O., Zuev S. Practice device artificial improvement basis of soil technologies jet grouting // Procedia Engineering. 2016. - № 165. - P. 504-509. URL: https://doi.org/ 10.1016/j.proeng.2016.11.726 (дата обращения 28.12.2020).

7. Bernard E.S., Thomas A.H. Fibre reinforced sprayed concrete for ground support // Tunnelling and Underground Space Technology. - 2020. - № 99. - P. 103-108. URL: https://doi.org/ 10.1016/j.tust.2020.103302 (дата обращения 28.12.2020).

8. Combining steam injection with hydraulic fracturing for the in situ remediation of the unsaturated zone of a fractured soil polluted by jet fuel / B. Nilsson, D. Tzovolou, M. Jeczalik, T. Kasela, W. Slack, K.E. Klint, F. Haeseler, C.D. Tsakiroglou // Journal of Environmental Management. - 2011. - № 92 (3). - P. 695-707. URL: https://doi.org/10.1016/j.jenvman.2010.10.004 (дата обращения 28.12.2020) стей достигает максимума; при большей скорости вращения (более $1,5 \mathrm{c}^{-1}$ ) наблюдались сильные вибрации и обвалы грунта.

3. Для небольших по ширине сооружений (10-20 м) при применении быстротвердеющих составов с минимальным временем набора пластической прочности допускается медленное бетонирование со скоростью 5-6 м/ч при угловой скорости $0,5 \mathrm{c}^{-1}$ и производительностью подачи раствора $30 \mathrm{~m}^{3} / 4$. Для сооружений большой ширины (40-60 м) подходят составы с быстрым набором пластической прочности, при этом скорость бетонирования должна быть максимальной (10-11 м/ч при угловой скорости $1,5 \mathrm{c}^{-1}$ и производительности подачи раствора $\left.50 \mathrm{~m}^{3} / \mathrm{q}\right)$.

4. Разработанная концепция шнековой технологии устройства противофильтрационных экранов, рассчитанные затраты труда и машинного времени позволяют использовать технологию в промышленном производстве.

9. Innovative technology of horizontal protective shield arrangement using injection / A. Meneylyuk, A. Petrovskiy, A. Borisov, A. Nikiforov // Electronic Journal of the Faculty of Civil Engineering Osijek (e-GFOS). - 2017. - № 15. - P. 36-49. URL: https://doi.org/10.13167/2017.15.4 (дата обращения 28.12.2020).

10. Seepage protection of irrigation canals using horizontal directional drilling / A. Meneylyuk, A. Petrovskiy, A. Borisov, A. Nikiforov // Tehnički glasnik - Technical Journal (TG-TJ). - 2017. - № 4 (11). P. 201-209. URL: https://hrcak.srce.hr/index.php?show= clanak\&id_clanak_jezik=281597 (дата обращения 28.12.2020).

11. Галинский А.М., Чернухин А.М., Менейлюк А.И. Совершенствование конструктивно-технологических решений локализации источников загрязнения грунтов // Вісник Одеської державної академії будівництва і архітектури. - 2016. - № 63. C. 309-315. URL: http://nbuv.gov.ua/UJRN/Vodaba_2016_63_53 (дата обращения 28.12.2020).

12. Zayed T., Mahmoud M. Data acquisition and factors impacting productivity of horizontal directional drilling HDD // Tunnelling and underground space technology. - 2013. - № 33. - P. 63-72. URL: https://doi.org/10.1016/j.tust.2012.08.005 (дата обращения 28.12.2020)

13. Hungerford F., Ren T. Directional drilling in unstable environments // International Journal of Mining Science and Technology. - 2014. - № 24 (3). - P 397-402. URL: https://doi. org/10.1016/j.ijmst.2014.03.019 (дата обращения 28.12.2020).

14. Meneylyuk A., Nikiforov A. Optimization of managerial, organizational and technological solutions of grain storages construction and reconstruction // Tehnički glasnik - Technical Journal (TG-TJ). - 2020. - № 2 (14). - P. 121-134. URL: https://doi.org/10.31803/tg-20190313150308 (дата обращения 28.12.2020)

15. Designing plaster mortar for a high-rise building / Z. Kos, V. Paruta, O. Gnyp, L. Lavrenyuk, I. Grynyova // Tehnički glasnik Technical Journal (TG-TJ). - 2019. - № 4 (13). - P. 331-336. URL: https://doi.org/10.31803/tg-20181206210501 (дата обращения 28.12.2020).

16. Kalmus H. The design and analysis of experiments // Annals of Eugenics. - 1952. - № 17 (1). - P. 96-97. URL: https://doi.org/10.1111/j.1469-1809.1952.tb02500.x (дата обращения 28.12.2020).

17. Таблицы планов эксперимента для факторных и полиномиальных моделей / В.3. Бродский, Л.И. Бродский, Т.И. Голикова, Е.П. Никитина, П.А. Панченко. - М.: Металургия, 1982. 753 p. URL: https://www.twirpx.com/file/789483/ (дата обращения 28.12.2020)

18. Biju M.S., Arnepalli D.N. Effect of biopolymers on permeability of sand-bentonite mixtures // Journal of Rock Mechanics and Geotechnical Engineering. - 2020. - № 12 (5). - P. 1093-1102. 
URL: https://doi.org/10.1016/j.jrmge.2020.02.004 (дата обращения 28.12.2020).

19. Effects of bentonite on pore structure and permeability of cement mortar / H. Yang, D. Long, L. Zhenyu, H. Yuanjin, Y. Tao, H. Xin, W. Jie, L. Zhongyuan, L. Shuzhen // Construction and Building Materials. - 2019. - № 224. - P. 276-283. URL: https://doi.org/10.1016/j.conbuildmat.2019.07.073 (дата обращения 28.12.2020).
20. Holmboe M., Wold S., Petterson T. Effects of the injection grout silica sol on bentonite // Physics and Chemistry of the Earth. 2011. - № 36 (17-18). - P. 1580-1589. URL: https://doi.org/10.1016/j.pce.2011.07.026 (дата обращения 28.12.2020)

Поступила 30.06.2021 г.

\section{Информация об авторах}

Менейлюк А.И., доктор технических наук, профессор, заведующий кафедрой технологии строительного производства Одесской государственной академии строительства и архитектуры.

Никифоров А.Л., кандидат технических наук, ассистент кафедры технологии строительного производства Одесской государственной академии строительства и архитектуры.

Менейлюк И.А., кандидат техничеких наук, докторант кафедры технологии строительного производства Харьковского национального университета строительства и архитектуры.

$\boldsymbol{P y c c ы и ̆ ~ B . B . , ~ а с п и р а н т ~ к а ф е д р ы ~ т е х н о л о г и и ~ с т р о и т е л ь н о г о ~ п р о и з в о д с т в а ~ О д е с с к о и ̆ ~ г о с у д а р с т в е н н о и ̆ ~ а к а д е м и и ~}$ строительства и архитектуры. 
UDC 699.85:621.039.743

\title{
ARRANGEMENT OF UNDERGROUND ANTI-FILTRATION SHIELDS USING PILOT WELLS AND AUGER DEVICE
}

\author{
Aleksandr I. Meneylyuk ${ }^{1}$, \\ meneilyk@gmail.com \\ Aleksey L. Nikiforov ${ }^{1}$, \\ nikiforov.aleksey@yahoo.com \\ Ivan A. Meneylyuk2, \\ ivmen11112019@gmail.com
}

\author{
Viktor V. Russyi ${ }^{1}$, \\ viruswot@gmail.com \\ 1 Odesa State Academy of Civil Engineering and Architecture, \\ 4, Didrikhsona street, Odesa, 65029, Ukraine. \\ 2 Kharkiv National University of Civil Engineering and Architecture, \\ 40, Sumskaya street, Kharkiv, 61000, Ukraine.
}

Relevance. One of the ways to ensure ecological safety is the localization of existing and potential sources of pollution by enclosing shield arrangement. For this, it seems rational to install underground anti-filtration shields under the source of pollution, preventing the emission of radioactive waste into the environment, in particular, the pollution of groundwater. This study is devoted to the development of auger technology for arrangement of anti-filtration shield, which consists of pilot holes made by the horizontal directional drilling, which is followed by the arrangement of a waterproof layer by replacing the soil with special concrete solution by auger.

The aim of the research is the experimental substantiation of the efficiency of the auger technology for construction of underground antifiltration shields to ensure the radiation safety of facilities.

Object: installation of underground anti-filtration shields using auger technology.

Methods: experimental statistical modeling, laboratory experiment, correlation and regression analysis.

Results. For structures of small width (10-20 m), slow concreting is allowed at a speed of 5-6 m/h (angular speed of 1,5 s-1 and feed rate of the composition of $\left.50 \mathrm{~m}^{3} / \mathrm{h}\right)$. For structures with a large width (40-60 m), there are suitable compositions with a long time of plastic strength at a concentration of fiber (9\%), bentonite (5\%) and water glass (6\%). In this case, the speed of concreting should be maximum $\left(10-11 \mathrm{~m} / \mathrm{h}\right.$ at an angular speed of $0,5 \mathrm{~s}^{-1}$ and feed rate of the composition of $\left.30 \mathrm{~m} / \mathrm{h}\right)$. The extremely high speed of concreting is achieved at an angular speed of 1,5 s-1 and a pulling force of 50,96 N. A further increase in the angular speed is not advisable, since at a higher angular speed (more than 1,5 $\mathrm{s}^{-1}$ ), strong vibrations and ground falls were observed. These experimental results made it possible to develop technological recommendations for construction of anti-filtration shields using auger technology. Namely, to develop a concept and procedure of works, to calculate the costs of labor and machine time.

\section{Key words:}

Ecological safety, auger technology, horizontal directional drilling, anti-filtration shield, experimental statistical modeling.

\section{REFERENCES}

1. Bugai D., Skalskyy A., Dzhepo S., Kubko, Y., Kashparov V., Van Meir N., Martin-Garin, A. Radionuclide migration at experimental polygon at Red Forest waste site in Chernobyl zone. P. 2: Hydrogeological characterization and groundwater transport modeling. Applied Geochemistry, 2012, vol. 27 no. 7, pp. 1359-1374. Available at: https://doi.org/10.1016/j.apgeochem.2011.09.028 (accessed 28 December 2020).

2. Roux C., Le Gal La Salle C., Simonucci C., Van Meir N., Keith Fifield L., Diez O., Lancelot J. High 36Cl/Cl ratios in Chernobyl groundwater. Journal of Environmental Radioactivity, 2014, vol. 138, pp. 19-32. Available at: https://doi.org/10.1016 /j.jenvrad.2014.07.008 (accessed 28 December 2020).

3. Le Gal La Salle C., Aquilina L., Fourre E., Jean-Baptiste P., Michelot J.-L., Roux C., Lancelot J. Groundwater residence time downgradient of Trench No. 22 at the Chernobyl Pilot Site: Constraints on hydrogeological aquifer functioning. Applied Geochemistry, 2012, vol. 27 no. 7, pp. 1304-1319. Available at: https://doi.org/10.1016/j.apgeochem.2011.12.006 (accessed 28 December 2020).

4. Shcheglov A., Tsvetnova O., Klyashto A. Biogeochemical cycles of Chernobyl-born radionuclides in the contaminated forest ecosystems. Long-term dynamics of the migration processes. Journal of Geochemical Exploration, 2014, vol. 144 no. B, pp. 260-266.
Available at: https://doi.org/10.1016/j.gexplo.2014.05.026 (accessed 28 December 2020).

5. Shui-Long Shen, Zhi-Feng Wang, Suksun Horpibulsuk, YongHyun Kim. Jet grouting with a newly developed technology: The Twin-Jet method. Engineering Geology, 2013, vol. 152 no. 1, pp. 87-95. Available at: https://doi.org/10.1016/j.enggeo.2012.10.018 (accessed 28 December 2020).

6. Makovetskiy O., Zuev S. Practice Device Artificial Improvement Basis of Soil Technologies Jet Grouting. Procedia Engineering, 2016, vol. 165, pp. 504-509. Available at: https://doi.org/10.1016/ j.proeng.2016.11.726 (accessed 28 December 2020).

7. Bernard E.S., Thomas A.H. Fibre Reinforced Sprayed Concrete for Ground Support. Tunnelling and Underground Space Technology, 2020, vol. 99, pp. 103-108. Available at: https://doi.org/10.1016/ j.tust.2020.103302 (accessed 28 December 2020).

8. Nilsson B., Tzovolou D., Jeczalik M., Kasela T., Slack W., Klint K.E., Haeseler F., Tsakiroglou C.D. Combining steam injection with hydraulic fracturing for the in situ remediation of the unsaturated zone of a fractured soil polluted by jet fuel. Journal of Environmental Management, 2011, vol. 92 no. 3, pp. 695-707. Available at: https://doi.org/10.1016/j.jenvman.2010.10.004 (accessed 28 December 2020).

9. Meneylyuk A., Petrovskiy A., Borisov A., Nikiforov A. Innovative technology of horizontal protective shield arrangement using injection. Electronic Journal of the Faculty of Civil Engineering 
Osijek (e-GFOS), 2017, vol. 15, pp. 36-49. Available at: https://doi.org/10.13167/2017.15.4 (accessed 28 December 2020).

10. Meneylyuk A., Petrovskiy A., Borisov A., Nikiforov A. Seepage protection of irrigation canals using horizontal directional drilling. Tehnički glasnik - Technical Journal (TG-TJ), 2017, vol. 4 no. 11, pp. 201-209. Available at: https://hrcak.srce.hr/index.php?show= clanak\&id_clanak_jezik=281597 (accessed 28 December 2020).

11. Galinskiy A.M., Chernukhin A.M., Meneylyuk A.I. Sovershenstvovanie konstruktivno-tekhnologicheskikh resheniy lokalizatsii istochnikov zagryazneniya gruntov [Improvement of constructive and technological solutions for localization of sources of soil pollution]. Bulletin of the Odessa State Academy of Building and Architecture, 2016, vol. 63, pp. 309-315. Available at: http://nbuv.gov.ua/UJRN/Vodaba_2016_63_53 (accessed 28 December 2020).

12. Zayed T., Mahmoud M. Data acquisition and factors impacting productivity of horizontal directional drilling HDD. Tunnelling and underground space technology, 2013, vol. 33, pp. 63-72. Available at: https://doi.org/10.1016/j.tust.2012.08.005 (accessed 28 December 2020)

13. Hungerford F., Ren T. Directional drilling in unstable environments. International Journal of Mining Science and Technology, 2014, vol. 24 no. 3, pp. 397-402. Available at: https://doi.org/ 10.1016/j.ijmst.2014.03.019 (accessed 28 December 2020).

14. Meneylyuk A., Nikiforov A. Optimization of managerial, organizational and technological solutions of grain storages construction and reconstruction. Tehnički glasnik - Technical Journal (TG-TJ), 2020, vol. 2 no. 14, pp. 121-134. Available at: https://doi.org/ 10.31803/tg-20190313150308 (accessed 28 December 2020).

15. Kos Z., Paruta V., Gnyp O., Lavrenyuk L., Grynyova I. Designing plaster mortar for a high-rise building. Tehnički glasnik - Tech- nical Journal (TG-TJ), 2019, vol. 13 no. 4, pp. 331-336. Available at: https://doi.org/10.31803/tg-20181206210501

16. Kalmus H. The Design and Analysis of Experiments. Annals of Eugenics, 1952, vol. 17, no. 1, pp. 96-97. Available at: https://doi.org/10.1111/j.1469-1809.1952.tb02500.x ～(accessed 28 December 2020).

17. Brodskiy V.Z., Brodskiy L.I., Golikova T.I., Nikitina E.P., Panchenko L.A. Tablitsy planov eksperimenta dlya faktornykh i polinomialnykh modeley [Experiment design tables for factorial and polynomial models]. Moscow, Metallurgiya, 1982.753 p. Available at: https://www.twirpx.com/file/789483/ (accessed 28 December 2020).

18. Biju M.S., Arnepalli D.N. Effect of biopolymers on permeability of sand-bentonite mixtures. Journal of Rock Mechanics and Geotechnical Engineering, 2020, vol. 12 no. 5, pp. 1093-1102. Available at: https://doi.org/10.1016/j.jrmge.2020.02.004 (accessed 28 December 2020).

19. Yang H., Long D., Zhenyu L., Yuanjin H., Tao Y., Xin H., Jie W., Zhongyuan L., Shuzhen L. Effects of bentonite on pore structure and permeability of cement mortar. Construction and Building Materials, 2019, vol. 224, pp. 276-283. Available at: https://doi.org/10.1016/j.conbuildmat.2019.07.073 (accessed 28 December 2020).

20. Holmboe M., Wold S., Petterson T. Effects of the injection grout silica sol on bentonite. Physics and Chemistry of the Earth, 2011, vol. 36, no. 17-18, pp. 1580-1589. Available at: https://doi.org/ 10.1016/j.pce.2011.07.026 (accessed 28 December 2020).

Received: 30 June 2021.

\section{Information about the authors}

Aleksandr I. Meneylyuk, Dr. Sc., professor, Head of Department, Odesa State Academy of Civil Engineering and Architecture.

Aleksey L. Nikiforov, Cand. Sc., assistant, Odesa State Academy of Civil Engineering and Architecture.

Ivan A. Meneylyuk, Cand. Sc., doctoral student, Kharkiv National University of Civil Engineering and Architecture. Viktor V. Russyi, postgraduate student, Odesa State Academy of Civil Engineering and Architecture. 